\title{
Article
}

\section{Engaging Publics: Biodiversity Data Collection and the Geographies of Citizen Science}

Toogood, Mark

Available at http://clok.uclan.ac.uk/9043/

Toogood, Mark ORCID: 0000-0003-2403-0338 (2013) Engaging Publics: Biodiversity Data Collection and the Geographies of Citizen Science. Geography Compass, 7 (9). pp. 611-621. ISSN 1749-8198

It is advisable to refer to the publisher's version if you intend to cite from the work. http://dx.doi.org/10.1111/gec3.12067

For more information about UCLan's research in this area go to http://www.uclan.ac.uk/researchgroups/ and search for < name of research Group>.

For information about Research generally at UCLan please go to http://www.uclan.ac.uk/research/

All outputs in CLoK are protected by Intellectual Property Rights law, including Copyright law. Copyright, IPR and Moral Rights for the works on this site are retained by the individual authors and/or other copyright owners. Terms and conditions for use of this material are defined in the policies page.

\section{CLoK}

Central Lancashire online Knowledge www.clok.uclan.ac.uk

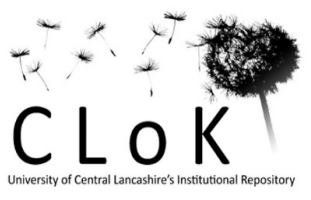




\title{
Engaging Publics: Biodiversity Data Collection and the Geographies of Citizen Science
}

\author{
Mark Toogood* \\ School of Built and Natural Environment, University of Central Lancashire
}

\begin{abstract}
This article addresses issues surrounding the role of public participation in expert-driven biodiversity monitoring and research, reviewing a range of cross-disciplinary insights and critiques that are important for recent debate in environmental geographies. The paper identifies normative, instrumental and substantive motivations dimensions of such initiatives and examines the tensions within these. A key focus concerns the 'win-win' model of public participation in scientific research (PPSR); claims of multiple benefits from PPSR, such as increased knowledge of biodiversity issues and of participants' local environments; claims that doing PPSR is a form of 'social learning'; and suggestions that engagement in science will change attitudes and environmental behaviour. The 'win-win' model is found to veil important issues about the politics of knowledge. These include the framing of citizenship in 'citizen' science, the production of certain kinds of scientific subjects within PPSR, the framing of relationships between professional and non-professional parties, assumptions about the role of 'data' in the rational evidenced-based process and anxieties amongst professional scientists around relations between data quality and the breadth of participation. Whilst the affective engagement with subject and the non-human world in PPSR is rich and diverse and the expert, non-expert boundary a mutable one (particularly in natural history), there is increasing contention that the win-win model for PPSR only works if we overlook aspects of these knowledge politics.
\end{abstract}

\section{Introduction}

Non-scientists getting involved in initiatives in which they do science, or public participation in scientific research (PPSR), are regarded both as having significant, even necessary, potential for biodiversity conservation (Secretariat of the Convention on Biological Diversity, 2010; House of Lords Science and Technology Committee, 2008; Dickinson and Bonney, 2012; Shirk et al., 2012; Hopkins and Freckleton, 2002). Current PPSR and their historical precedents are also intriguing because of the encounters between professionals and nonprofessionals in the co-production of knowledge (Macdonald, 2002; Ellis and Waterton, 2004, 2005; Toogood, 2011).

In relation to recent PPSR initiatives questions arise, which are highly relevant for environmental geography, about the politics of biodiversity and society. These areas of interrogation includes inquiry into what knowledge is being produced, about the practices that make up such knowledge-making, the interactions between different individual and institutional actors and, indeed, about the rationale and assumptions behind such types of public engagement (Stringer et al., 2006). This paper aims, through exploration of literature across science and technology studies (STSs) and in environmental geographies, to review issues about volunteer publics in science, particularly in biological data collection, monitoring, analysis and conservation. Through this, it will engage with the already lively discussion in geography about agenda setting, knowledge making and decision making and the rationales and purposes of the politics of public participation in science. 
A starting point for this discussion is a range of literature concerned with science and publics, which criss-cross the boundaries of geography and STS (Irwin, 1995; Chilvers, 2008, 2009, 2010; Tsouvalis and Waterton, 2012; Lawrence, 2006, 2009; Reed, 2008), particularly social studies of ecology and society, and biodiversity conservation (Caissie and Halpenny, 2003; Evans, 2004; Ellis and Waterton, 2004, 2005; Bell et al., 2008). Over the last 20 years, the increase in, and attention to, the participation of non-expert publics in various forms, from engagement with science though doing science, to policy deliberation, has constituted a 'participatory turn' (Fiorino, 1990; Irwin, 2001; Irwin and Michael, 2003). Much of the debate in such literature addresses concerns, on the one hand, about the 'deficit model' in which the diffusion of scientific knowledge is assumed to flow from experts to a knowledge-deficient public. This notion of a public deficit originated in the 1980s through government concern with creating a 'pro-science' public through education (Royal Society, 1985; Durant et al., 1999). On the other hand, a shift in the last decade has seen a shift of emphasis from whether people understand science, to advocating people's participation in science. Researchers have considered active participation to be part of a participatory turn, or to be examples of a normative 'dialogic turn' in which 'experts and target-groups are reconfigured as participants in sites of dialogue where knowledge is co-produced through mutual learning' (Phillips et al., 2012, 3, original emphasis).

Many public bodies now attempt to involve a range of social actors in a variety of participatory schemes. A distinction might be made between initiatives based on public participation in making scientific knowledge (in the sense of doing the empirical work of collection or monitoring, for example) and those schemes in which the public do not get involved in doing the science itself, but instead have a deliberative role about science, technology and innovation in ways that are more normatively framed and future-oriented (Wilsden and Willis, 2005). In the former case, individuals may get involved in the direct creation of knowledge, particularly through observation of nature. For example, many volunteer scientists are involved in long-standing schemes for counting birds and also in schemes for monitoring planets. On the other hand, participation has also included the public in deliberating issues as miscellaneous as scenarios for wetland habitat restoration, the limits of stem cell research, the development of nanotechnology and the control of biotechnology in food systems (Burgess et al., 2007; Davies, 2006). Increasingly, institutions have been keen to promote and fund the latter mode of engagement through a series of schemes, with non-governmental organisations (such as universities, museums, and wildlife conservation and recording organisations) organising individuals into networks that 'do' science. The non-professional has also been enrolled into government-sponsored PPSR, such as in rolling public monitoring of local soil variations for a British Geological Survey/Centre for Ecology and Hydrology (through a GPS-based smartphone app) and within a UK Lottery-funded programme called Open Air Laboratories (OPAL). Some of these initiatives are extremely large scale. OPAL, for example, has involved about 500000 non-experts in seven biodiversity and environmental since 2007, some based on use of the iSpot species identification and verification app (Davies et al., 2011; Davies et al., 2013).

The distinction between deliberating upon and doing science is a messy one, even in the relatively well-defined area of science such as biodiversity monitoring and policy. Participation seemingly has a broad and diffuse boundary. As Jason Chilvers points out,

Participation is a highly contested term that means different things to different people. To add to the confusion participation is often called (or equated to) many different things such as 'engagement', 'empowerment', 'involvement', 'consultation', 'deliberation', 'dialogues', 'partnership', 'outreach', 'mediation', 'consensus building' and 'civic science'. The list goes on. $(2009,401)$ 
Whether a short one-off 'bioblitz' or on-going field survey, enrolment of the public is, from the promoter's point of view, seemingly done for reasons as diverse as follows: to acquire data, to promote better understanding of science generally and to facilitate a public right to be involved in science; and, still, to 'educate' the public in issues and to advance a connection between data and 'improved' biodiversity policy. Promoters self-identify themselves in distinctively mission-oriented ways and suggest a win-win connection between those dimensions of PPSR noted above. Concerns about this are quite varied, including the following: that the participatory mode forecloses a more complex and perhaps more sophisticated public engagement with environmental politics (Wynne, 2007); that the sorts of people doing PPSR might exclude certain socio-economic groups (Michael, 2009); about the degree to which PPSR makes any difference, either to scientific commitments to its engagement with policy, or to policy and governance generally (Felt and Fochler, 2010); and to what extent PPSR schemes are 'trivial' or provide a public relations 'gloss' for scientific agendas (Thorpe and Gregory, 2010).

This article will, albeit in relatively broad terms, review the implications of PPSR as a 'win-win' mode of public engagement. It does this through engagement with three aspects of participation beginning with an examination of motivations for PPSR. The second section examines the relationship between 'amateur' and 'expert'. This involves questions about who is qualified to 'do' science, about the value of non-expert knowledge and about scientific evidence as the basis of official policies and action. Thirdly, the article moves on to review PPSR in the light of a criticisms that engagement can be framed by pre-existing concerns (such as technoscientific modes of problem definition and evidence-based policy) and arguments that expert rationalities 'mine' participants for their contributions thereby reinforcing particular models of science and allowing decision makers to close down debate. The last section of the article briefly considers examples of 'experimental' modes of engagement.

\section{Rationales for Public Engagement}

There are three main rationales for expert-driven science initiatives doing science to involve the public. The first is the normative rationale that regards public involvement as democratic and therefore positive in itself. This apparently idealistic assessment is justified on the basis that science is publicly funded and affects everyone's lives; therefore, the public has an inherent interest in what science does, especially in respect of concerns around environmental change. This runs deeper than taxpayer interest in that there is a public right to influence science and its outcomes, particularly through creating and sustaining effective communication and understanding between experts, politicians, regulators and the public (Chilvers 2009). This ties more broadly to the role of science in society and, from the early 1970 s, increasing public disenchantment with science as unproblematically and inherently trustworthy (Ezrahi, 1990). For several commentators, the trend towards participation in science is, in fact, a trend towards re-establishing science as a legitimate arbiter of public policy (Leadbeater and Miller, 2004).

Second, there are instrumental rationales for public participation that include, for example, increasing the geographical completeness of data, or so that the public can participate in education about biodiversity. In the case of the aforementioned OPAL programme, gaining direct understanding of the environment through PPSR was advanced as a way of equipping the public with 'confidence and knowledge to debate environmental issues' (Davies et al., 2013, p. 11). Such initiatives, despite such normative claims, follow the traditional idea that survey and monitoring involving non-expert participants is relatively straightforward: a volunteer 'informed' or 'trained' public, following professionally established protocols, and doing 
scientific labour, typically recording data that is sent to professionals for analysis (Bonney et al., 2009). Broadly, the public engagement process feeds a professional analytic process.

Such public participation in biological monitoring has a long and diverse history that stems from the transformation of 'the amateur tradition' (Allen, 1976). The history of 'amateurs' making natural history observations and knowledge is heterogeneous. Numerous studies have documented a wide variation in populist and elitist natural histories emerging in various geographical and historical contexts (Lowe, 1976; Keeney, 1992; Drouin and BensaudeVincent, 1996; Secord, 1994; Marren, 1995; Macdonald, 2002; Toogood, 2011). The gentlemanly and populist natural history of the Victorian and Edwardian era in the UK, for example, shifted to a more extensive, systematically organised and sustained pattern of amateur-expert networks in the 20th century. In such arrangements, geographically distributed volunteers would acquire the necessary knowledge and skills through processes of acculturation into natural history including, inter alia, auto-didactic study and repeated practice [such as use of nomenclature and taxonomic keys, optical technology, and acquisition of abilities in 'flash' recognition of species (Ellis, 2011)] and peer mentoring. A key example of the result of such modes of organisation is the public-professional networks related to bird distributions and populations. Greenwood (2007) suggests that volunteers collect about $70 \%$ of British bird records and volunteer ornithology involves around 1.5 million person-hours per annum. Surveys of nearly all flora and fauna taxa have conventionally relied on committed nonprofessionals, some of whom, over long 'careers' as amateur recorders have become local, regional, national or even international experts on particular taxa in their own right (Allen, 1976). This 'amateur-professional partnership' has significance as

he decline in natural history work in the twentieth century (especially in the second half) in terms of professional status and funding has paradoxically coincided with a huge increase in concern for biodiversity and the environment [...].Given this, it is fortunate that the amateurs have been on hand to fill the gap. (Greenwood, 2007, p. S101)

The third rationale is what can be termed an 'optimal' or 'substantive' rationale which suggests that public involvement results in more open, publicly accountable science, particularly around specific large-scale issues (Leach et al., 2005). This sort of rationale has its roots in responses to a series of national controversies that were marked by public mistrust around the putative misinformation, denials and lack of accountability of science. These include, for example, incidents concerning nuclear power, animal disease and welfare, and biotechnology. Since the early 1980s, state policy-makers have been enthusiastic about 'public participation in science', and increased participation in various forms has been regarded as a steady progression away from the domination of science by experts.

These rationales can contain variable expectations and assumptions about particular participatory projects and the roles of different publics and experts within them. As Tsouvalis and Waterton (2012, p. 113) note:

This diversity of rationales matters, because the kind of rationale adopted makes a significant difference to the participatory practices adopted: each one supports very different philosophical approaches to expertise and knowledge, as well as different kinds of encounter between lay people and those conventionally considered experts.

One common linking thread between rationales is the notion of achievability, the idea that PPSR can achieve simultaneous and coterminous benefits, for data generation, education and democracy, otherwise known as the win-win model (Cohn, 2008). The next 
section picks up on this framing of PPSR by addressing discussions in geography and other disciplinary areas about the place of lay people in PPSR and the notion of collaboration in knowledge production.

\section{Expert and Non-expert in Participatory Science}

There have been different assessments of the role of non-experts in participatory initiatives. As previously mentioned, such assessments vary in relation to different types of participation. A fine-grained analysis of practices of participation suggests that further issues are important: the instrumental value of participation to policy; the construction and enrolment of a suitable 'participant public'; the definition of issues, or of the non-human nature to be considered; the interactions of people in practice with the roles, protocols and rules defined by professionals; and the definition of what 'success' is in relation to these initiatives (Lezaun and Soneryd, 2007; Felt and Fochler, 2010).

The idea that participatory monitoring of biodiversity creates an unequivocally 'win-win' scenario is based upon the recognition of certain key values: the instrumental value of monitoring for data analysis, the affective qualities of knowledge for the individual participant, the normative value placed on science by individuals and the transformative effects possible for individuals (Lawrence, 2006, 2009; Lawrence and Turnhout, 2010). In this kind of analysis, non-professionals have competences and skills that complement and contribute to those of professionals. PPSR in biodiversity is thereby a sort of hybrid forum, where an interweaving of benefits for professional organisers, public policy and public participants takes place resulting in high value (win-win) interactions and outputs.

Other studies place a more critical emphasis on the politics, or de-politicisation of PPSR. A general background to studies of the politics of the co-production of knowledge imagines the possibility, or impossibility, of the so-called 'critical- interpretative model' in which the public is configured as a valid collaborator providing an important counterpart to professional science (Callon, 1999). The assumption that PPSR as a kind of 'collaboration' engenders deeper knowledge relevant to 'correct' environmental politics flowing from scientific understanding is, for some commentators, suspiciously like a worrying reassertion of deficit modelstyle science (Bucchi and Neresini, 2008). The optimism for a win-win in terms of scientific participation equalling scientific understanding, equalling enhanced political competences, is not a given equation but something more like a location of contestation that can include public participants being at odds the roles allocated to them within PPSR.

In a detailed study of citizen science monitoring of sea-turtles in the USA, for example, Cornwell and Campbell (2011) evaluated the political dimension of PPSR in practice. In the study, volunteer scientists described their motivations for involvement as related to the notion of human impact on species life-cycles and intrusion on habitats. Cornwell and Campbell show that volunteers held the assumption that the science-policy nexus has an intrinsic importance but that their inclusion specifically was framed by the professional organisers to situate 'collaboration' as outside of that nexus. Participants' participation was assumed by experts in charge of the programme to end with data recording, as well as interaction with species. Policy was regarded by the expert organisers as across a borderland, one which PPSR did not allow direct access. Volunteer scientists knew that this division of science away from policy was an artifice and that policy was crucial to turtle ecology. PPSR thus framed what participation was and what it was not.

A UK study of public participation in natural history monitoring examined a taxonomic data initiative run by the Natural History Museum in London. The research demonstrated that the participation of non-experts was defined within a top-down framework that limited 
the ways even knowledgeable amateurs could affect outcomes for the data they contributed (Ellis and Waterton, 2004, 2005). Expert definition of how public participation works in practice was also a dimension of research into volunteer bird monitoring in Scotland (Lorimer, 2007, 2008). In this PPSR, participants' engagement with nature was reduced and focused through the very specific requirements of pro-forma data sheets designed by experts. In these three studies, it was shown that the requirements set by expert organisers effectively reinforced pre-existing assumptions about how non-experts should relate to nature, data and policy. In the case of the US turtle PPSR study, it was interesting to note that the participants resisted the definition of their roles as outside of decision making:

While the volunteers did not tackle the canon of scientific knowledge or claim epistemic equality with scientists, they asserted their knowledge in decision-making processes for their beach zones and partook in the co-production of conservation practices. In the context of the collaboration...[T]he volunteers were able to bring their knowledge of sea turtles to bear on management practices, and their rendering of sea turtles and conservation became part of the conservation process. (Cornwell and Campbell, 2011, p. 115).

Although the participants in the studies by Ellis and Waterton $(2004,2005)$ and Lorimer (2008) were locally situated and intimately engaged in knowing their local 'patches', these studies suggested that participants' experience was, in contrast to the above study, 'framed out' of influencing policy by the implicit boundaries set by experts through programme assumptions, structures and apparatus.

The question of authority is also important. Cornwell and Campbell (2011) regard it as a positive outcome if participants can actively see their data being utilised in policy. This may be a rather one-dimensional process: collaboration with the singular purpose of providing data for others to discover and follow trends in biodiversity. This assumes a defining role for organisers of PPSR in defining what forms of knowing are included and excluded. Critics contend that this dominant framing limits scope for other possible forms of engagement that might well go outside the model within the dominant idea of PPSR (Evans, 2004). If PPSR is preconfigured, say commentators, then participation can exclude other completely relevant forms of engagement such as argument, debate and different forms of collaboration, which might count as non-expert knowledge making.

The win-win benefits claimed for PPSR emerging as a by-product of the primary emphasis on knowledge production also precludes attention to wider factors at play in the scientific policy process (Cooke and Kothari, 2001; Marris and Rose, 2010; Wynne, 2007). Critics contend that policy makers, even whilst claiming wide-ranging holistic benefits for PPSR, may see science as narrowly defined, as a ready-made set of issues, bounded and constrained, or pre-framed (Stirling, 2008; Swyngedouw, 2010; Bucchi, 2010; Demeritt et al., 2009). The role of the public can be framed within this as non-negotiable, disallowing a simultaneous critique of the science-policy process. In programmes that emphasise a particular notion of doing science, the deliberative element of participation is removed. People's concerns about biodiversity loss, for example, might be given a context through the PPSR process, but may not be able to be included as serious contributions within that same process. Whilst actors with access to other means, different types of social or cultural capital, might use different routes to engage with biodiversity politics, the citizenship within such PPSR may actually reduce public awareness of political questions about biodiversity and frame relationships in ways that reinforce the distance between scientists and citizens.

Within STS, there has been an ongoing debate about how to place the public in debates about science, and in participation in knowledge production, that avoids problems 
of pre-framing - in which participants are constrained by the assumptions and pre-existing commitments of technocratic institutions concerning what an 'uneducated' public can usefully contribute (Fischer, 2000; Elam and Bertilsson, 2003; Chilvers, 2010; Felt and Fochler, 2010). To the latter problem, Wynne (2007) asserts that publics are often well ahead: their concerns frequently relates to features of science that are highly 'educated' and often inherently political (concerning science's ability to control the environment, to predict changes in nature, concerning science policy and its direction, and about contingencies in science, technology and innovation). The assumption that the public are scientifically under-informed continues, however, to be regarded as a rationale of precluding meaningful public contribution into debate (Thorpe and Gregory, 2010).

\section{Experiments with Participation in Science}

Certain visions of science and policy advocate experimentation and inventiveness rather than consensus building (Bogner, 2012; Lane et al., 2010). These 'experiments' advocate deliberative forms of participation that are more attuned to democratic rather than instrumental approaches to PPSR: publics are empowered to deliberate the purposes of the project, what constitutes relevant data, and so on. For their advocates, these initiatives go beyond the putative limitations of instrumental rationales in much PPSR, highlighting 'those features of the [...] scientific public engagement event that are typically forgotten, bracketed, sanitized' (Michael, 2012, p.544) and thereby exploring the make-up of the 'scientific citizen' and the engagement process.

The Loweswater Care Project (LCP) (Waterton et al., 2006; Tsouvalis and Waterton, 2012) demonstrates one example of experiment. The LCP was formed in 2006 to address the issue of eutrophication in a Cumbrian lake. It included organisational stakeholders and local residents working with ecologists and social scientists to create a collective vision of what a healthy lake would be. From the outset the LCP worked openly to avoid the pitfalls of PPSR in a

[F]orum that both critically questioned forms and 'frames' of expertise, whilst simultaneously trying to construct and bring together appropriate forms of knowledge, data, understanding and experience for examination, scrutiny and possible use.... It experimented with being a new participatory 'social mechanism', a critical space for the co-production of knowledge, and it did so in ways which began to look more positive about the possibility of scientific and other knowledges working together. (Tsouvalis and Waterton, 2012, p. 117)

Any future attempts at developing large-scale biodiversity monitoring programmes could usefully seek to draw from the approaches developed in such experiments and to build upon these to encourage more of an opening-up of knowledge-politics in PPSR. The biggest limitation upon such an approach might be the willingness of publics to be thus engaged in such open-ended experiment. Those involved in the LCP would have all had some kind of personal or professional involvement with and interest in the lake and the surrounding area. In the US Turtle PPSR study, the 'ownership' of the project was strongly connected to place and indeed was at the heart of debate over what should be done with the data. There is no formula that professionals can use to orchestrate scientific surveys of biodiversity that predictably and controllably produce an emotional connection with individuals in their locality. Yet, naturalists, both novice and experienced, seem obviously and intimately connected to place. Questions around matters of scale, place, science and affectiveness should provide continuing future areas of research in this area of geography. 


\section{Conclusion}

This article has traced some of the developments and debates around public participation in environmental geographies with a focus on biodiversity. Participation goes well beyond simply being enrolled into a scheme, for many it becomes a 'serious pursuit' that can continue over a lifetime (Stebbins, 1992, 2008). There are over 20 million regular adult volunteers in England (DCLG, 2011, 8), and many others dedicated to a serious pursuit outside of their working lives. This notion of a sort of vibrant 'knowledge-force' of unpaid, hybrid, researchers represents for some an optimistic model of knowledge creation:

'Knowledge, once held tightly in the hands of professionals, will start to flow into networks of dedicated amateurs. The crude, all or nothing, categories we use to carve up society - leisure versus work, professional versus amateur - will need to be rethought. [The serious amateurs] will bring new forms of organisation into life, which are collaborative, networked, light on structure and largely self-regulating. [T] he new driving force, creating new streams of knowledge, new kinds of organisations, new sources of authority will be the Pro-Ams. (Leadbeater and Miller, 2004, 71)'

Public participation in science is often held to have a double benefit - or win-win benefits - for the organising professional bodies and also for individual public participants. These include reasoning which claims that public participation will help to create the next generation of authoritative amateur monitors of the environment (which has been a concern amongst government policy-makers), to get people involved in outdoor activities, to boost scientific education, and, most prominently, to utilise various publics as data gatherers.

However, much research also recognises the complexities, compromises and limitations that particular philosophies of the public and of science have for participants as citizen scientists, and also for the professional scientists involved. Large PPSR projects frequently claim normative potentialities. In practice, this potential tends to be realised as certain citizen scientist identities come to be situated in relationship to that of the expert scientist. Yet, wider issues of power are always at play. The term participation itself raises many questions about the legitimacies of different kinds of knowledge in politics and decision making, and cannot be reduced to processes defined by non-professionals 'doing' science or taking part in particular forms of collaboration. The question of participation opens up questions about what public participation means for science and science's role in public policy (Ezrahi, 1990; Jasanoff, 2004). The democratisation of participatory science in biodiversity, for example, raises questions beyond motivation and benefits. It suggests questions about the definition of public engagement, about agenda setting, about what data is gathered, about the subjectivities of those involved and, most of all, about the connections between the role of the on-the-ground volunteer scientist and decision-making processes concerning biodiversity, its protection and its future.

\section{Short Biography}

Dr Mark Toogood is Senior Lecturer in Human Geography at University of Central Lancashire. His recent research includes the historical geography of ecological science, and the mobilisation of publics as observers in inter-war ornithology and in Mass-Observation.

\footnotetext{
Note

*Correspondence address: Mark Toogood, University of Central Lancashire, School of Built and Natural Environment, Preston, PR12HE, UK. E-mail: mtoogood@uclan.ac.uk
} 


\section{References}

Allen, D. E. (1976). The naturalist in Britain, a social history. London: Allen and Lane.

Bell, S., Marzano, M., Cent, J., Kobierska, H., Podjed, D., Deivida Vandzinskaite, D., Reinert, H., Armaitiene, A., Grodzinska-Jurczak, M., and Mursic, R. (2008) What counts? Volunteers and their organisations in the recording and monitoring of biodiversity. Biological Conservation 17, pp. 3443-3454.

Bogner, A. (2012). The paradox of participation experiments. Science, Technology and Human Values 37(5), pp. 506-527.

Bonney, R., Cooper, C. B., Dickinson, J., Kelling, S., Phillips, T., Rosenberg, K. V. and Shirk, J. (2009). Citizen science: a developing tool for expanding scientific knowledge and science literacy. Bioscience 59, pp. 977-984.

Bucchi, M. (2010) Beyond technocracy: science, politics and citizens. New York: Springer.

Bucchi, M., and Neresini, F. (2008). Science and public participation. In Hackett, E., Amsterdamska, O., Lynch, M. and Wajcman, J. (eds) The handbook of science and technology studies. Cambridge, MA: The MIT Press, 3rd edition, pp. 449-472.

Burgess, J., Clark, J., Davies, G., Eames, M., Mayer, S., Staley, K., Stirling, A., and Williamson, S. (2007). Deliberative mapping: exploring a new analytic-deliberative methodology. Public Understanding of Science 16 (3), pp. 299-322.

Caissie, L. T., and Halpenny, E. A. (2003). Volunteering for nature: motivations for participating in a biodiversity conservation program. World Leisure Journal 45(2), pp. 38-50.

Callon, M. (1999). The role of lay people in the production and dissemination of scientific knowledge. Science, Technology and Society 4(1), pp. 81-94.

Chilvers, J. (2008). Environmental risk, uncertainty, and participation: mapping an ergent epistemic community. Environment and Planning A 40, pp. 2990-3008.

Chilvers, J. (2009). Deliberative and participatory approaches in environmental geography. In: Castree, N., Demeritt, D., Livermann, D. and Rhoades, B., (eds), A companion to environmental geography. Oxford: Blackwell, pp. 400-417.

Chilvers, J. (2010). Sustainable participation? Mapping out and reflecting on the field of public dialogue on science and technology. Harwell: ScienceWise Expert Resource Centre.

Cohn, J. P. (2008). Citizen science: can volunteers do real research? BioScience 58 (3), pp. 192-197.

Cooke, B. and Kothari, U. (2001). Participation: the new tyrrany? London: Zed Books.

Cornwell, M. L. and Campbell, L. M. (2011). Co-producing conservation and knowledge: citizen-based sea turtle monitoring in North Carolina, USA. Social Studies of Science 42(1), pp.101-120.

Davies, G. (2006). Mapping deliberation: calculation, articulation and intervention in the politics of organ transplantation. Economy and Society 33, pp. 232-258.

Davies, L., Bell, J. N. B., Bone, J., Head, M., Hill, L., Howard, C., Hobbs, S. J., Jones, D. T., Power, S. A., Rose, N., Ryder, C., Seed, L., Stevens, G., Toumi, R., Voulvoulis, N. and White, P. C. L. (2011). Open Air Laboratories (OPAL): a community-driven research programme. Environmental Pollution 159(8-9), pp. 2203-2210.

Davies, L., Gosling, L., Bachariou, C., Eastwood, J., Fradera, R., Manoumaiudom, N. and Robbins, S. (eds) (2013). OPAL community environment report. London: Imperial College.

DCLG (2011). Citizenship survey, 2011. London: Department for Communities and Local Government.

Demeritt, D., Dyer, S. and Millington, J. D. A. (2009). PEST or Panacea? Science, Democracy, and the Promise of Public Participation, Environment, Politics and Development Working Paper Series number 10. London: Department of Geography, King's College, University of London.

Dickinson, J. L. and Bonney, R. (eds) (2012). Citizen science: public participation in environmental research. Ithaca, NY: Cornell University Press.

Drouin, J.-M. and Bensaude-Vincent, B. (1996). Nature for the people. In Jardine, N., Secord, J. and Spary, E. (eds) Cultures of natural history. Cambridge: Cambridge University Press, pp. 408-425.

Durant, J., Evans, G. and Thomas, G. (1999). The public understanding of science. Nature 340, pp. 11-14.

Elam, M. and Bertilsson, M. (2003). Consuming, engaging and confronting science: the emerging dimensions of scientific citizenship. European Journal of Social Theory 6, pp. 233-251.

Ellis, R. (2011). Jizz and the joy of pattern recognition: virtuosity, discipline and the agency of insight in UK naturalists' arts of seeing. Social Studies of Science 41(6), pp. 769-790.

Ellis, R. and Waterton, C. (2004). Environmental citizenship in the making: the participation of volunteer naturalists in UK biological recording and biodiversity policy. Science and Public Policy 31(2), pp. 95-105.

Ellis, R. and Waterton, C. (2005). Caught between the cartographic and the ethnographic imagination: the whereabouts of amateurs, professionals and nature in knowing biodiversity, Environment and Planning D: Society and Space 23(5), pp. 673-693.

Evans, J. (2004). What is local about local environmental governance? Observations from the local biodiversity action planning process. Area 36(3), pp. 270-279.

Ezrahi, Y. (1990). The desecent of Icarus. Science and the transformation of contemporary democracy. Cambridge, MA: Harvard University Press.

Felt, U. and Fochler, M. (2010). Machineries for making publics: inscribing and describing publics in public engagement. Minerva 48(3), pp. 219-238. 
Fiorino, D. J. (1990). Citizen participation and environmental risk: a survey of institutional mechanisms. Science Technology and Human Values 15(2), pp. 226-243.

Fischer, F. (2000). Citizens, experts and the environment. The politics of local knowledge. Durham, NC: Duke University Press. Greenwood, J. J. D. (2007). Citizens, science and bird conservation. Journal of Ornithology 148(Suppl. 1), pp. S77-S124.

Hopkins, G. W. and Freckleton, R. P. (2002). Declines in the numbers of amateur and professional taxonomists: implications for conservation. Animal Conservation 5: 245-249.

House of Lords Science and Technology Committee, (2008). Systematics and taxonomy: follow-up. 5th Report of Session 2007-2008, HL Paper 162. London: TSO.

Irwin, A. (1995). Citizen science: a study of people, expertise and sustainable development. Routledge: Routledge.

Irwin, A. (2001). Constructing the scientific citizen: science and democracy in the biosciences. Public Understanding of Science 10, pp.1-18.

Irwin, A. and Michael, M. (2003). Science, social theory and public knowledge. Maidenhead: Open University Press/ McGraw Hill.

Jasanoff, S. (2004). Science and citizenship: a new synergy. Science and Public Policy 31(2), pp. 90-94.

Keeney, E. (1992). The botanizers: amateur scientists in nineteenth-century America. Chapel Hill, NC: University of North Carolina Press.

Lane, S., Odoni, N., Landström, C., Whatmore, S., Ward, N., and Bradley, S. (2010). Doing flood risk differently: an experiment in radical scientific method. Transactions of the Institute of British Geographers 36(1), pp. 15-36.

Lawrence, A. (2006). "No personal motive?" Volunteers, biodiversity and the false dichotomies of participation. Ethics, Place \& Environment 9(3), pp. 279-298.

Lawrence, A. (2009) The first cuckoo in winter: phenology, recording, credibility and meaning in Britain. Global Environmental Change 19, pp. 173-179.

Lawrence, A. and Turnhout, E. (2010). Personal meaning in the public sphere: the standardisation and rationalisation of biodiversity data in the UK and the Netherlands. Journal of Rural Studies 26, pp. 353-360.

Leach, M., Scoones, I., and Wynne, B. (2005). Science and citizens: globalisation and the challenge of engagement. London: Zed Books.

Leadbeater, C. and Miller, P. (2004). The pro-am revolution: how enthusiasts are changing our economy and society. London: Demos.

Lezaun, J. and Soneryd, L. (2007) Consulting citizens: technologies of elicitation and the mobility of publics. Public Understanding of Science 16(3), pp. 279-297.

Lorimer, J. (2007). Nonhuman charisma. Environment and Planning D: Society and Space 25(5), pp. 911-932.

Lorimer, J. (2008). Counting corncrakes: the affective science of the UK corncrake census. Social Studies of Science 38(3), pp. 377-405.

Lowe, P. (1976). Amateurs and professionals: the institutional emergence of British plant ecology. Journal of the Society for the Bibliography of Natural History 7, pp. 517-535.

Macdonald, H. (2002). What makes you a scientist is the way you look at things: ornithology and the observer, 1839-1955. Studies in History and Philosophy of Biological and Biomedical Sciences 33, pp. 53-77.

Marren, P. (1995). The new naturalists. Collins: London.

Marris C. and Rose N. (2010). Open engagement: exploring public participation in the biosciences. PLoS Biology, 8(11): e1000549, November.

Michael, M. (2009). Publics performing publics: of PiGs, PiPs and politics. Public Understanding of Science 18, pp. 617-631.

Michael, M. (2012). What are we busy doing?” Engaging the idiot. Science, Technology and Human Values 37(5), pp. 528-554.

Phillips, L., Carvalho, A. and Doyle, J. (2012). Introduction. In Phillips, L., Carvalho, A. and Doyle, J. (eds). Citizen voices: performing public participation in science and environment communication. Bristol: Intellect, pp. 3-17.

Reed, M. (2008). Stakeholder participation for environmental management: a literature review. Biological Conservation 141, pp. 2417-2431.

Royal Society (1985). The public understanding of science. London: The Royal Society.

Secord, A. (1994). Science in the pub: artisan botanists in early nineteenth-century Lancashire. History of Science 32 , pp. 269-315.

Secretariat of the Convention on Biological Diversity, (2010). Guide to the global taxonomy initiative. CBD Technical Series number 30. New York, NY: United Nations.

Shirk, J. L., Ballard, H. L., Wilderman, C. C., Phillips, T., Wiggins, A., Jordan, R., McCallie, E., Minarchek, M., Lewenstein, B. V., Krasny, M. E. and Bonney R. (2012). Public participation in scientific research: a framework for deliberate design. Ecology and Society 17(2), p. 29 http://dx.doi.org/10.5751/ES-04705-170229

Stebbins, R. A. (1992). Amateurs, professionals and serious leisure. Montreal: McGill-Queen's University Press.

Stebbins, R. A. (2008). Serious leisure. A perspective for our time. New Brunswick, NJ: Transaction.

Stirling, A. (2008). "Opening up" and "closing down": power, participation, and pluralism in the social appraisal of technology. Science, Technology and Human Values 33(2), pp. 262-294. 
Stringer, L., Dougill, A., Fraser, E., Hubacek, K., Prell, C. and Reed, M. (2006). Unpacking “participation” in the adaptive management of social-ecological systems: a critical review. Ecology and Society 11(2), 39 (online).

Swyngedouw, E. (2010). Apocalypse forever? Post-political populism and the spectre of climate change. Theory, Culture and Society 27(2-3), pp. 213-232.

Thorpe, C. and Gregory, J. (2010). Producing the post-Fordist public: the political economy of public engagement with science. Science as Culture 19, pp. 273-301.

Toogood, M. (2011). Modern observations: new ornithology and the science of ourselves, 1920-1940. Journal of Historical Geography 37, pp. 348-357.

Tsouvalis, J. and Waterton, C. (2012). Building 'participation' upon critique: the Loweswater Care Project, Cumbria UK. Environmental Modelling and Software 36, pp. 111-121.

Waterton, C., Norton, L., Morris, J. (2006). Understanding Loweswater: interdisciplinary research in practice. Journal of Agricultural Economics 57(2), pp. 277-293.

Wilsden, J. and Willis, R. (2005). See through science: why public engagement needs to mode upstream. London: Demos.

Wynne, B. (2007). Public participation in science and technology: performing and obscuring a political-conceptual category mistake. East Asian Science, Technology and Society 1, pp. 99-110. 